\title{
Factors Delaying the Adoption of Civil Drones: A Primitive Framework
}

\author{
Johnny Chamata \\ Faculty of Business, Curtin University Malaysia \\ CDT 250 \\ Miri, Sarawak 98009, Malaysia \\ e-mail: johnny.chamata@gmail.com
}

\begin{abstract}
The literature on the acceptance or adoption of unmanned aircraft, aka civil drones, is scarce and under-developed. The majority of literature discusses several social concerns, whereas only little research promotes economic concerns. Additionally, the literature does not consider existing technology acceptance theory, but arbitrarily investigates the acceptance of several applications. This research discusses both social and economic concerns and establishes for a conceptual framework for predicting the public acceptance of drones. The conceptual framework considers the contemporary issues (i.e. social and economic concerns) and is based on risk theory. It proposes that the perception of risk associated with the use of drones influence the public acceptance of the technology. Social and economic concerns, in turn, are proposed as constituents of perceived risk. The proposed model establishes for further theoretical development and empirical assessment in pursue of deeper explanation of the factors which influence public acceptance. The research concludes with stating limitations and proposing recommendations for future research.
\end{abstract}

Keywords: drones, social factors, economic factors, adoption framework.

\section{Introduction}

The concept of unmanned aircraft goes back to the Ming Dynasty around 450 B.C., where the Chinese used it in religious rituals as well as in the battlefield ${ }^{1}$. In modern history, it is believed that the first use of unmanned aircraft was during the Great $\mathrm{War}^{2}$. It is noteworthy though that research on unmanned aircraft began around 425 B.C. by Archytas of Tarentum ${ }^{3}$ and was developed through the years by the work of people such as Hassan Al Rammah ${ }^{4}$, Leonardo Da Vinci ${ }^{1,3}$, Mikhail Lomonosov ${ }^{3}$ and many others.

The thought of employing unmanned aircraft in civil applications was not initiated until the 1970s, when they were experimented as solar-powered airplanes ${ }^{3}$. Nowadays, there is an evident technological necessity for the deployment of unmanned aircraft ${ }^{5}$. Aside from their use in military contexts to reduce casualties and deaths of military personnel ${ }^{6}$, drones are employed in hundreds of applications from telecommunications and agriculture to conservation and disaster management and many others ${ }^{7}$.

Today, statistics show that drone sales are significantly increasing ${ }^{8,9,10}$. These statistics correlate positively with research findings in the very little drone adoption literature; which generally shows a moderate [conditional] level of acceptance for the technology in the United States ${ }^{11,12}$, Canada ${ }^{13}$ and Australia ${ }^{14}$.

Unmanned aerial systems (UAS) can be of great benefit in many cases. Let us take an example of monitoring high tension towers where usually a helicopter with up to six personnel on-board are employed to survey thousands of kilometers. The use of unmanned aerial vehicles (UAV) instead, can substantially reduce costs of hiring the helicopter and paying the personnel's wages, and may reduce the risks of injury or maybe life loss ${ }^{15}$. Another example is the ambulance drone, which is capable of saving people suffering cardiac arrest ${ }^{16}$.

There are also great economic hopes laid on the unmanned aircraft industry. It is predicted to generate huge outcomes, be it by increasing employment or revenues ${ }^{17,18,19,20}$. For instance, the European Union considers this industry as one of the determinants of its 2020 economic aspirations ${ }^{21}$. Observable also is an economic movement. Recently, a strategic alliance was established between NASA, Google and 100 academic and business organizations to design a UAS-based traffic management system ${ }^{22}$. Additionally, the UAS industry is innovating: several organizations, in 2015, developed autonomous drones able of tracking the 
person's movement ${ }^{23,24,25}$, usually used in recreational activities. The industry has also diversified through the development of supersized drones (i.e. flying cars) capable of carrying passengers ${ }^{26}$. Despite these economic potentials, several challenges lie ahead the progress of unmanned aircraft adoption. The literature as broadly discussed technical, legal, and societal issues, showing a delay in its adoption by different means. Ref. 19 claims that this delay is harmful for the economy as every year of adoption delay costs billions of dollars.

The literature though does not establish clear connections between the delay of UAS adoption and these issues. Moreover, very little has been done relating to the possible economic reasons behind this delay. This study then combines socio-economic factors aiming to provide a holistic view of the slow adoption of unmanned aircraft. The author proposes that social and economic concerns of the public contribute to the delay of UAS adoption. This proposition is further developed by consulting risk theory which promotes perceived risk as the sole determinant of technology acceptance.

Thus, this paper is outlined as follows: an introduction is provided to explain the research background and problem statement; followed by a discussion of current social and economic concerns. Moreover, risk theory is discussed in further detail and the connection between concerns and public acceptance is theoretically established. Accordingly, a conceptual framework is proposed. The model exhibits that social and economic concerns are constituents of perceived risk, which in turn influences the acceptance of drone technology.

\subsection{Research Significance}

This study is considered significant because it suggests connections between the social and economic concerns associated with UAS technology and the delay of its adoption; believed to not been discussed in literature previously. Academically, the outcomes of this research may establish the foundations for future UAS literature which shall possibly consider a dual socio-economic perspective [rather than the increased focus on social issues]. The research also contributes to theory as it is the first to propose a conceptual model which predicts public acceptance. Proposing a relationship between perceived risk and public acceptance establishes for further theory development and empirical assessment. Practically, this research may indirectly increase the awareness of different stakeholders (e.g. entrepreneurs, policymakers) and assist them exerting more directed efforts towards advancing the UAS industry.

\section{Literature Review}

\subsection{Societal Factors}

Several public and official concerns towards the use of UAS in national airspace are reported in the literature. Such concerns are causing harmful reactions towards the technology. In the following, more details are given:

\subsubsection{Privacy Concerns}

Unmanned aircraft are superbly capable devices which are useful on both the individual and business levels. Their relatively small size allows them to fly over places that humans ${ }^{27}$ or alternative technologies such as helicopters or manned aircraft cannot. They are also capable of taking photographs and video captures from different angles ${ }^{28}$ and to stay aloft undetected ${ }^{29}$. These aircraft may be also equipped with thermal cameras allowing them to detect objects beyond line of $\operatorname{sight}^{27}$.

However, when these capabilities are at times accompanied with ethical misconduct, increased privacy concerns are evident. In many cases, residential and private spaces are invaded whereas it is not possible to identify or track down the drone operator. Concerns have been also raised about UAS commercial activities such as marketing, private investigation, and journalism $^{30}$. With the media desiring unique images and videos to attract more audience, it is not surprising to witness an abuse of privacy by paparazzi rather than drone journalists ${ }^{27,28}$. Several incidents occurred over the past few years including filming Kate Middleton and Paris Hilton with no prior consent ${ }^{28}$.

Ref. 31 explains that the problem lies in the dynamic means UAS collect data, and in their ability to access areas inaccessible for other technologies, which marks them as harmful monitoring tools. Opposing opinions see that privacy concerns are overstated while other more intrusive technologies exist, such as CCTV and mobile phones ${ }^{31}$, which makes them not the only devices with mounted cameras ${ }^{30}$. 'For decades, public authorities throughout the world have made use of helicopters and manned aircraft, equipped with cameras, to carry out [...] surveillance' Ref. 20 affirms. Nonetheless, other research expects that privacy concerns will disappear over time, as the public will acquire more knowledge on the technology 49 .

But, what are people worried about? Research claims that people are concerned about the destiny and destination of their personal data and being identified. Bodily privacy is essentially important to the public because it compromises personal freedom which has undesirable influence on innovative behaviors necessary 
for economic growth ${ }^{71}$. Additionally, the public is concerned about privacy of their locations and communication [e.g. email, mobile calls] which UAS are also capable of monitoring through a communication link ${ }^{72}$.

Ref. 31 proposes a privacy by design concept which necessitates that UAS designs, prior to manufacturing, in a proactive and preventive manner, should consider alleviating privacy concerns. When this concept is embedded in designs, UAS are expected to monitor areas which mandate surveillance and will identify less details of someone's face. Additionally, videos will be destroyed after mission is accomplished.

\subsubsection{Safety Concerns}

Looking at the technical deficiencies of unmanned aircraft, we find that they still are not equipped with certain technologies that warrant public safety. For instance, UAV designs do not include failure mode or a fallback system ${ }^{28}$. Research assures the importance of integrating such systems to ensure safe landing in case of emergencies (e.g. power cut-off, flight instability, etc.). Additionally, designs do not consider sense-andavoid functions necessary for the safety of other airplanes operating in national airspace. While there are suggestions of using the ADS-B technology which allows broadcasting precise aircraft location and path to air traffic controllers, the idea is not yet used ${ }^{30}$.

There have been various incidents which increased concerns about the reliability and safety of using unmanned aircraft. Most recently, in November 2015, an 18 months old British toddler lost one of his eyes after being hit by a drone flown by a family friend. 'Oscar Webb's eye was sliced in half by a propeller' and will require 'several operations before he can have a prosthetic eye fitted ${ }^{32}$. In 2011, another $£ 13 \mathrm{~K}$ police drone broke over the River Mersey during a routine training due to failed emergency landing ${ }^{33}$. In the United States, Google's massive Solara50 (designed to deliver internet services) crashed shortly after take-off at a test site in New Mexico ${ }^{34}$. And many more incidents are found in the news $\mathrm{s}^{35,36}$.

Ref. 28 argues that concerns about UAS operations are comparable to other technologies (e.g. manned aircraft). Alternatively, he perceives that the real issue is about untrained pilots who are not skilled enough and lack knowledge of drone regulations. However, the high costs of investigating reckless piloting behaviours stand in the way of holding them accountable ${ }^{37}$.
However, recently, spoofing technologies were introduced by the U.S. Department of Homeland Security to facilitate controlling a drone which poses risks to safety. The thousand-dollar-worth technique ${ }^{69}$ depends on making the drone receive false GPS signals from the hackers instead of the satellite, and be directed to the destination they choose ${ }^{68}$. More effective are jamming techniques which overwhelm the drone with GPS signals causing it to stop functioning ${ }^{69}$.

Ref. 50 proposes the concept of ethical design, which permits the aircraft to endure tough weather and technical shortcomings. In his views, UAS should not make decisions autonomously, but a pilot should always be put in loop. Ref. 30 proposes the implementation of safety objectives. Safety objectives include forecasting hazards, investigating a pilot's flight record ${ }^{51}$, and assessing the aircraft's technical reliability prior to a flight $^{30}$.

\subsubsection{Security Concerns}

Furthermore, drones because of being a flexible and easy-to-tame technology become vulnerable to the use in mischievous activities ${ }^{28}$ and raise security concerns from civil authorities (e.g. law enforcement). Authorities are worried about employing unmanned aircraft in criminal and terrorist acts especially that they are difficult to detect or stop ${ }^{38}$. These concerns were upheld over the past few years.

In 2014, more than 30 UAVs were flown over different areas of a nuclear reactor in southern France for unclear purposes. Oda Becker, a nuclear consultant, expressed concerns that these drones might be spying in preparation for an attack ${ }^{39}$. In 2011, an American citizen was arrested for planning to launch an attack on the Pentagon and the U.S. Capitol using drones loaded with remotely controlled explosives ${ }^{40}$. The suspect also identified other sites in Washington D.C. for similar attacks $^{41}$. Many other incidents may have taken place and not reported. It has been claimed that, since 2011, the authorities of the United States, Germany, Spain, and Egypt have thwarted at least six terrorist droneattacks $^{38}$.

Several authors discuss security concerns and provide rationale behind such attacks. Ref. 70 claims that employing military drones in unregulated strikes in the Middle East plays a major role in instigating terror attacks using civil drones. Because of these strikes some are motivated for revenge and are even gaining more public compassion, he expounds. Ref. 52 explains that these strikes have severe psychological impacts on people: 'but the scandalous mistakes $[\ldots .$.$] cannot so$ 
easily be erased from public memory [of the Middle Eastern]' ... '[a strike hit] impoverished innocents scavenging for saleable metal fragments from the earlier bombardments' (p.17).

\subsubsection{Implications of Societal Concerns}

These social concerns, in many instances, have implications on UAT adoption. First, unmanned aircraft are being banned access to national airspace. Famous instances include bans in U.S. national parks ${ }^{42}$ and in Indian airspace ${ }^{43}$. Second, drone flights in some instances are provoking citizens who are in return reacting violently towards them ${ }^{44}$. Last, aviation authorities are being reluctant or maybe hesitant in setting laws to regulate the use of unmanned aircraft. The U.S. Federal Aviation Administration (FAA), for example, which promised a clear regulatory framework for operating drones in the United States by September 2015, has just delivered one in June last year ${ }^{45}$. Similarly, several EU countries have either not finished developing regulations or are not showing interest ${ }^{46}$. Authors of Ref. 47 argue that regulations have influence on the rate of technology adoption. Similarly, findings from Ref. 48 show that the strictness of regulations negatively influences technology adoption.

\subsection{Economic Concerns}

Ref. 5 investigates the status of unmanned aircraft industry revealing interesting findings among which is that the UAS industry lacks rivalry. The author, based on industrial reports, showed that UAS profits and production distribution in North America alone are almost three times as the rest of the world; that is, \$2.7 billion followed by Europe with $\$ 780$ million while the rest of the world merely produces a sum of $\$ 280$ million. Moreover, he noted that there is also a huge gap in the number of manufacturers worldwide, between Europe, Asia-Pacific and North America from one side and South America and Africa from the other (See Figure 1).

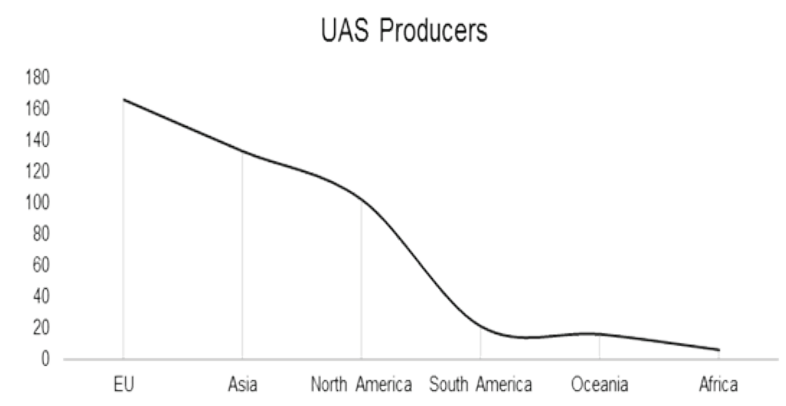

Fig. 1. UAS manufacturers per continent - Source: Chamata (2016)
The same research predicts that the UAS industry is more likely to experience high investment reluctance (or it might be happening) because of elevated business risks associated with the technology. The current research proposes that these business risks include the several issues debated earlier herewith (i.e. technical and ethical issues, concerns, bans and regulations). This may also provide an interpretation for the intercontinental gap in UAS production. Additionally, Ref. 5 considers that entrepreneurs may be reluctant to invest because of the fear of job loss and destruction of staff skills.

\section{Theoretical Background: Risk Theory}

Risk is a central issue in technology management ${ }^{53,54}$, it has the power of stimulating and demising industries ${ }^{54}$. However, risk theory was not employed in consumer research until Raymond Bauer (1960) introduced it to the marketing discipline; beforehand it was used in research on economics and psychology [see Ref. 55, 56, 57]. It has advanced since then and has been used to predict the acceptance of several technologies ${ }^{58}$.

Bauer (1960) proposed that risk arises from unexpected, indefinite and unpleasant consequences resulting from a product purchase ${ }^{59}$. Whereas uncertainty is reflected in this definition, Peter and Rayan (1976) propose that perceived risk relies on a person's evaluation of 'expected' loss and thus also holds a certainty component ${ }^{60}$. A general definition is provided by Ref. 61 'perceived risk in marketing is the nature and amount of risk perceived by a consumer in contemplating a particular purchase action'.

Disciplines, other than consumer research, make a distinction between unexpected and expected risk. For instance, economic research considers risk a consequence of high expectation of risk occurrence ${ }^{57}$. Nonetheless, it also reflects the existence of a probability distribution of 'uncertain' outcomes ${ }^{62}$. The nature of perceived risk holding both certainty and uncertainty has implications on risk acceptability discussed in the following paragraphs.

Risk acceptability is the core of research which employs risk theory. The fundamental quest in understanding risk acceptance is to evaluate "how safe is safe enough?"54. Ref. 54 explain that risk acceptance depends on the level of risk [or perceived risk] associated with an activity [e.g. purchase or use of a product]. This risk though equally produces some benefits to the individual or society. Thus, as Ref. 63 put it, acceptable risk is 'a function of benefits or other [...] characteristics. If the 
levels of risk meet acceptability criteria, the technology is considered acceptable ${ }^{63}$; otherwise, a risk-handling behaviour should take place to reduce the overall perceived risk to an acceptable level ${ }^{58}$.

The level of perceived risk depends on the level of anticipated hazard; the more serious the hazard is, the higher its perceived risk, the more likely a risk handling behaviour is to be desired ${ }^{64,65}$. Equally important in determining risk-handling behaviors is perceived benefit and the inability to tolerate losses ${ }^{64}$. Risk handling occurs when the risk held in an activity is higher than the acceptable level. Therefore, a person engages in risk reduction behaviors such as information search ${ }^{62}$ and education $^{58}$. Thus, reduced risk is merely an informed [or educated] version of the inherent risk, which implies the importance of informing and educating on new technologies [e.g. drones].

Hence, risk reduction is an informational ${ }^{62}$ and educational $^{58}$ process leading to a tradeoff between perceived risk and other characteristics of the product or service to reach risk acceptance. This leads us to think of a risk-benefit tradeoff ${ }^{54.63}$. Different forms of tradeoff exist: for instance, product characteristics ${ }^{63}$ such as class, brand, quality, and price were shown to moderate the level of inherent risk ${ }^{53}$. Moreover, product class, when one's interest is high, may be an alternative determinant of risk-reduction behaviors, rather than perceived risk ${ }^{64}$. The tradeoff may also happen within the risk components or types, reflecting an overall, acceptable or not, perceived risk ${ }^{66}$

It is important to note that perceived benefit is usually considered as a part of perceived risk ${ }^{63}$ rather than a salient and independent component; as per the perceived risk tradition ${ }^{57}$. Nonetheless, several authors consider perceived risk and perceived benefit as separate beliefs $^{54,57,58}$.

Five risk types or components exist, as proposed by Bauer (1960). These components: financial, social, functional, physical, and psychological; constitute the overall perceived risk ${ }^{66}$. Additionally, Ref. 67 proposed that time loss is also a form of risk [e.g. a life span: a year or two] important to measure risk acceptance. Recent research proposes other dimensions such as perceived personal risk [equivalent to safety risk in drone research], perceived privacy risk and perceived source risk $^{61}$ [i.e. being cheated by the selling firm].

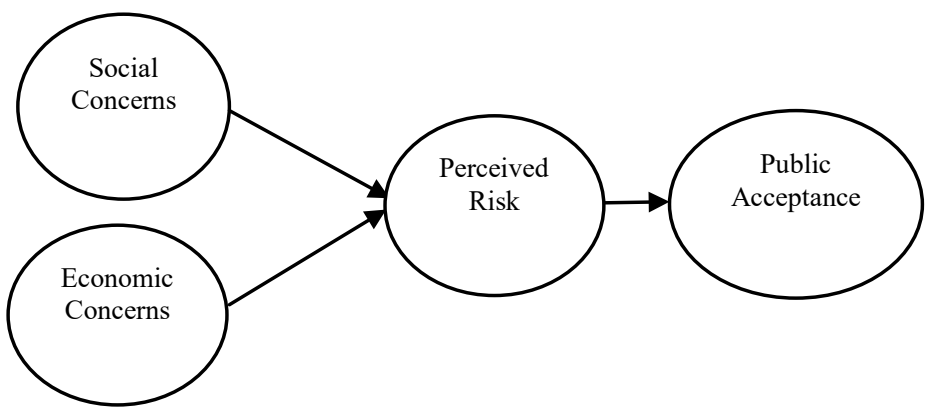

Fig. 2. Theoretical Framework

Thus, from this synthesis, we can conclude that perceived risk is a multidimensional construct $t^{57,62}$. The influence of each dimension or component, though, on the overall perceived risk depends on the context ${ }^{59}$. However, this influence is mediated by psychological risk $^{57}$ which means that a risk type which does not impact the consumer psychologically, may not have a significant influence on the overall perceived risk. In other words, if an economic risk [e.g. job and skill destruction], for example, is not of the consumer's concern, it will not account to their overall perception of a product's risk.

\section{Discussion}

In light of the above, and based on the review of literature, we can propose that the acceptance of civil drones is influenced by perceived risk which is, in case of concurrent issues, caused by social and economic concerns. Social risks are summarized in concerns about privacy, safety, and security. On the other hand, economic risks are characterized by investors' concerns about job replacement and skill destruction.

Such proposition is relevant to the current stream of research discussing social and economic concerns towards drone use, and suggests a relationship between concerns and the acceptance of drones, never been proposed previously. This establishes for theory development and incorporating additional constructs to explain or predict public acceptance. Other theories which promote more determinants of public acceptance may also be consulted.

As Fig. 2 depicts, social and economic concerns cause the rise of perceived risk, which presents it as a formative construct. However, concerns may be the reflection of the public's perceptions of risks associated with civil drones, and hence can be represented as a reflective construct. It really depends on the maturity and development of the risk components. When sufficient expression of concerns is obtained, then it is 
possible to provide a formative representation of the construct.

Relatedly, the scarce and under-developed drone literature encourages the search for research on public acceptance of other technologies. This may be helpful in construct development and validation. For instance, literature on genetically modified organisms is rich in research discussing the influence of perceived risk on public acceptance and provides previously validated measures. Nonetheless, it is noteworthy that several conceptual and operational modifications will be needed to suit the constructs to the drone context. An integration of drone literature may be useful.

\section{Conclusion}

This research aimed at explaining, based on concurrent issues and existing theory, the reasons or factors behind the delay of civil drone adoption. Literature review has shown that several social and economic concerns exist, however no influence was proposed on the delay of the technology's acceptance. The reviewed literature also did not, except for one article, consider a theoretical background for the research. However, this article did not test relationships between perceived risk and public acceptance.

The current research detailed the existing social and economic concerns, and broadly discussed risk theory. Based on that, the author developed a model which proposes that public acceptance is influenced by their perceptions of risks associated with drone use. The perceived risk was hypothesized as being composed of both social and economic concerns.

Due to the novelty of this UAS research and the absence of relevant material, this research often relied on industrial evidence, however, this may also be perceived as an advantage, as academic research was often validated by industrial facts. Additionally, this research has proposed a primitive model which paves the way for future research for further development. Due to time limitation, this research also left behind empirical validation of the proposed model. Future research may consider the development and empirical testing of constructs.

\section{Acknowledgment}

This research is funded by the Graduate School at Curtin University Malaysia. The author would like to thank the anonymous reviewers for their constructive feedback which contributed to the development of this paper in its optimum form.

\section{References}

1- Dalamagkidis, K. ; Valavanis, Kimon P.; Piegl, L. A. (2012). On integrating unmanned aircraft systems into the national airspace system (Second). Dordrecht: Springerlink + Business Media. http://doi.org/10.1007/978-94-007-2479-2

2- Valavanis, K. P., \& Vachtsevanos, G. J. (2015). Handbook of unmanned aerial vehicles. Handbook of Unmanned Aerial Vehicles, 1-3022. http://doi.org/10.1007/978-90-481-9697-1

3- Valavanis, K. P. (2007). Advances in Unmanned Aerial Vehicles. Dordrecht: Springer Netherlands.

4- Finn, A., \& Scheding, S. (2010). Developments and Challenges for Autonomous Unmanned Vehicles. (J. Kacprzyk \& L. C. Jain, Eds.). Berlin: Springer. http://doi.org/10.1007/978-3-64210694-7

5- Chamata, J.E. (2017). Convergence of the Unmanned Aerial Industry. Theoretical Economics Letters, 7, 175-186.

6- LeMieux, J. (2013). Drones and UAV entrepreneurship: 30 businesses you can start (First). Unmanned Vehicle University.

7- LeMieux, J. (2014). Drone: UAV Dictionary (First). Unmanned Vehicle University.

8- MilesGrimshaw. (2014). Data on The Consumer Drone Market. Retrieved from http://milesgrimshaw.com/data-drone-market

9- Forbes. (2015). Drone Sales Soar Past \$16 Million On eBay. Retrieved from http://www.forbes.com/sites/frankbi/2015/01/28/drone-salessoar-past-16-million-on-ebay/\#41a375924e6e

10- Drone Life. (2015). Drone Sales Numbers: Nobody Knows, So We Venture A Guess. Retrieved from http://dronelife.com/2015/04/16/drone-sales-numbers-nobodyknows-so-we-venture-a-guess/

11- Eyerman, J., Letterman, C., Pitts, W., \& Holloway, J. (2013) Unmanned Aircraft and the Human Element: Public Perceptions and First Responder Concerns.

12- Herron, K., Jenkins Smith, H., \& Silva, C. (2014). US Public Perspectives on Privacy, Security, and Unmanned Aircraft Systems, (March), 82.

13- Bracken-Roche, C., Lyon, D., Mansour, M. J., Molnar, A., Saulnier, A., \& Thompson, S. (2014). Surveillance Drones: Privacy Implications of the Spread of Unmanned Aerial Vehicles (UAVs) in Canada.

14- Clothier, R. A., Greer, D. A., Greer, D. G., \& Mehta, A. M. (2015). Risk Perception and the Public Acceptance of Drones. Risk Analysis, 1-17. http://doi.org/10.1111/risa.12330

15- Sebbane, Y. B. (2012). Lighter than Air Robots (First) Dordrecht: Springer Science + Business Media. http://doi.org/10.1007/978-94-007-2663-5

16- DailyMail. (2014). The ambulance drone that could save your life: Flying defibrillator can reach speeds of $60 \mathrm{mph}$. Retrieved from http:/www.dailymail.co.uk/sciencetech/article2811851/The-ambulance-drone-save-life-Flying-defibrillatorreach-speeds-60mph.html

17- Gibbens, D. (2014). EDITORIAL Integrating UAS into the oil and gas industry, (July).

18- Guiraud, M. and Nachescu, Miruna-Lucia. (2012). Drones as a tool of sustainable development - consequences of their usage and new forms of risk management 1, 12(4), 466-479.

19- Jenkins, D., \& Vasigh, B. (2013). The economic impact of unmanned aircraft systems integration in the United States, (March), 1-40. Retrieved from http://www.auvsi.org/econreport

20- Volovelsky, U. (2014). Civilian uses of unmanned aeria vehicles and the threat to the right to privacy - An Israeli case study. Computer Law and Security Review, 30(3), 306-320. http://doi.org/10.1016/j.clsr.2014.03.008

21- EU Business. (2014). Remotely piloted aviation systems, or drones. $\quad$ Retrieved from http://www.eubusiness.com/topics/transport/drones/?searchterm $=$ droneeconomy 
22- Russia Today. (2015). Google, NASA work together to design drone air-traffic-control system. Retrieved from https://www.rt.com/usa/310695-drone-air-traffic-control/

23- 3DR. (2016). 3DR Homepage. Retrieved from https://3dr.com/solo-drone/

24- $\mathrm{Hexo}^{+}$. (2016). Hexo+ Homepage. Retrieved from https://hexoplus.com/

25- Lily. (2016). Lily Homepage. Retrieved from www.lily.camera

26- Ehang. (2016). Ehang184 Homepage. Retrieved from http://www.ehang.com/ehang184

27- Galliot, J. C. (2012). Uninhabited systems in the civilian realm: Some ethical concerns [Commentary]. IEEE Technology and Society Magazine, 31(2), 13-16. http://doi.org/10.1109/MTS.2012.2202017

28- Clarke, R. (2014a). Understanding the drone epidemic. Computer Law and Security Review, 30(3), 230-246. http://doi.org/10.1016/j.clsr.2014.03.002

29- Calo, R. M. (2014). Robots and Privacy. In P. Lin, G. Bekey, \& K. Abney (Eds.), Robot Ethics: The Ethical and Social Implications of Robotics. MIT Press.

30- Elias, B. (2012). Pilotless Drones: Background and Considerations for Congress Regarding Unmanned Aircraft Operations in the National Airspace System. Congressional Research Service, 1 - 24. Retrieved from http://www.fas.org/sgp/crs/natsec/R42708.pdf

31- Cavoukian, Ann. (2012). Privacy and Drones: Unmanned Aerial Vehicles. Office of Privacy Commissioner, p. 1-27.

32- BBC. (2015). Toddler's eyeball sliced in half by drone propeller. Retrieved from http://www.bbc.com/news/ukengland-hereford-worcester-34936639

33- BBC. (2011). Police drone crashes into River Mersey. Retrieved from http://www.bbc.com/news/uk-englandmerseyside-15520279

34- Bloomberg. (2015). Google's Solar-Fueled Cyber Drone Crashes in New Mexico Test. Retrieved from http://www.bloomberg.com/news/articles/2015-05-29/google-ssolar-fueled-cyber-drone-crashes-during-new-mexico-test

35- Business Insider. (2013). Video Of Drone Crashing Into Cargo Plane In Afghanistan Raises Concern Over German UAV Safety. Business Insider. Retrieved from http://www.businessinsider.com/drone-crash-raises-concernover-safety-2013-7? IR=T

36- Sydney Morning Herald. (2014). "River of blood" after drone "hits" Australian Athlete. Retrieved from http://www.smh.com.au/technology/technology-news/river-ofblood-after-drone-hits-australian-athlete-20140407-zqruh.html

37- Clarke, R. (2014b). The regulation of civilian drones' impacts on public safety. computer law \& security review 30 , p. $230-$ 246.

38- The Wall Street Journal. (2015). Criminals, Terrorists Find Uses for Drones, Raising Concerns. Retrieved from http://www.wsj.com/articles/criminals-terrorists-find-uses-fordrones-raising-concerns-1422494267

39- DW. (2014). "Make thicker walls": Terrorism fears high as drones survey French nuclear reactors. Retrieved from http://www.dw.com/en/make-thicker-walls-terrorism-fearshigh-as-drones-survey-french-nuclear-reactors/a-18084893

40- Boston Globe. (2012). Rezwan Ferdaus of Ashland sentenced to 17 years in terror plot; plotted to blow up Pentagon, Capitol. Retrieved from http://archive.boston.com/metrodesk/2012/11/01/rezwanferdaus-ashland-sentenced-years-terrorplot/KKvy6D6n2PfXfbEfA4iMwJ/story.html

41- FBI. (2012). Man Sentenced in Boston for Plotting Attack on Pentagon and U.S. Capitol and Attempting to Provide Detonation Devices to Terrorists. Retrieved from https://archives.fbi.gov/archives/boston/pressreleases/2012/man-sentenced-in-boston-for-plotting-attack-on- pentagon-and-u.s.-capitol-and-attempting-to-providedetonation-devices-to-terrorists

42- Culver, K. B. (2014). From Battlefield to Newsroom: Ethical Implications of Drone Technology in Journalism. Journal of Mass Media Ethics, 29(1), 52-64. http://doi.org/10.1080/08900523.2013.829668

43- Director General of Civil Aviation. (2014). Use of Unmanned Aerial Vehicle (UAV)/ Unmanned Aircraft Systems (UAS) for Civil Applications.

44- NBC. (2015). Case Dismissed Against William H. Merideth, Kentucky Man Arrested For Shooting Down Drone. Retrieved from http://www.nbcnews.com/news/us-news/case-dismissedagainst-william-h-merideth-kentucky-man-arrested-shootingn452281

45- AUVSI. (2016). Out of the Net: FAA Releases Small UAS Rule. Retrieved from http://www.auvsi.org/blogs/auvsinews/2016/06/21/suasrule

46- Blyenburgh, P. Van. (2014). Civil RPAS' Usage, Regulation \& Certification In Europe Terms \& Information Sources What we are NOT talking about? What we ARE talking about Regulatory Responsibility RPAS - All Sizes \& Shapes Aerial Operations RPAS Regulations RPAS Certification Europea, (May).

47- Nurdin, N., Stockdale, R., \& Scheepers, H. (2012). The influence of external institutional pressures on local egovernment adoption and implementation: A coercive perspective within an indonesian local e-government context. Lecture Notes in Computer Science (Including Subseries Lecture Notes in Artificial Intelligence and Lecture Notes in Bioinformatics), 7443 LNCS, 13-26. http://doi.org/10.1007/978-3-642-33489-4 2

48- Briglauer, W. (2014). The impact of regulation and competition on the adoption of fiber-based broadband services: Recent evidence from the European union member states. Journal of Regulatory Economics, 46(1), 51-79. http://doi.org/10.1007/s11149-013-9237-4

49- Clothier, Reece. 2013. "UAS and Privacy - An Industry Problem?" Australian Association for Unmanned Systems. www.aaus.org.au/2013/04/01/uas-and-privacy-an-industryproblem

50- Asaro, Peter. 2013. "On Banning Autonomous Weapon Systems: Human Rights, Automation, and the Dehumanization of Lethal Decision-Making." International Review of the Red Cross 94 (886): 677-699. doi:10.1017/S1816383112000767.

51- Clothier, Reece, and Rodney Walker. 2006. "Determination and Evaluation of UAV Safety Objectives." 21st International Unmanned Air Vehicle Systems Conference 2006: 18.1-18.16.

52- 52 Satia, Priya. 2014. "Drones: A History from the British Middle East." Humanity: An International Journal of Human Rights, Humanitarianism, and Development 5 (1): 1-31. doi:10.1353/hum.2014.0002.

53- Bettman, Jr James R. 1973. "Perceived Risk and Its Components: A Model and Empirical Test." Journal of Marketing Research 10 (May): 184. doi:10.2307/3149824.

54- Fischhoff, Baruch, Paul Slovic, Sarah Lichtenstein, Stephen Read, and Barbara Combs. 1978. "How Safe Is Safe Enough A Psychomeric Study of Attitudes towards Technological Risks and Benefits." Policy Sciences 9 (2): 127-52. doi:10.1007/BF00143739.

55- Kahneman, Daniel, and Amos Tversky. 1979. "Prospect Theory: An Analysis of Decision Under Risk." Econometrica 47 (2).

56- Yaari, Menahem E . 1987. "The Dual Theory of Choice under Risk". The Econometric Society 55 (1): 95-115.

57- Stone, Robert N., and Kjell Gronhaug. 1993. "Perceived Risk Further Considerations for the Marketing Discipline." European Journal of Marketing 27 (3): 39-50. doi:http://dx.doi.org/10.1108/03090568310026637. 
58- Slovic, Paul. 1987. "The Perception of Risk." Science. doi:10.1126/science. 3563507.

59- Dholakia, Utpal. 2001. "A Motivational Process Model of Product Involvement and Consumer Risk Perception." European Journal of Marketing 35 (11/12): 1340-62.

60- Laroche, Michel, Zhiyong Yang, Gordon H G McDougall, and Jasmin Bergeron. 2005. "Internet versus Bricks-and-Mortar Retailers: An Investigation into Intangibility and Its Consequences." Journal of Retailing 81 (4): 251-66. doi:10.1016/j.jretai.2004.11.002.

61- Lim, Nena. 2003. "Consumers' Perceived Risk: Sources versus Consequences." Electronic Commerce Research and Applications 2 (1): 216-228. doi:10.1016/S15664223(03)00025-5.

62- Conchar, Margy P, George M Zinkhan, Cara Peters, and Sergio Olavarrieta. 2004. "An Integrated Framework for the Conceptualization of Consumers' Perceived-Risk Processing." Journal of the Academy of Marketing Science 32 (4): 418-36. doi:10.1177/0092069304266551.

63- Otway, Harry J., and Detlof Von Winterfeldt. 1982. "Beyond Acceptable Risk: On the Social Acceptability of Technologies." Policy Sciences 14 (3): 247-56. doi:10.1007/BF00136399.

64- Dowling; Graham R., and Richard Staelin. 1994. "A Model of Perceived Risk and Intended Risk - Handling Activity." Journal of Consumer Research 21 (1): 119-34. doi:10.1086/209386.

65- Slovic, Paul, and Elke U Weber. 2002. "Perception of Risk Posed by Extreme Events." In Risk Management Strategies in an Uncertain World, 1-21. New York.
66- Jacoby, Jacob, and Leon B. Kaplan. 1972. "The Components of Perceived Risk." In SV - Proceedings of the Third Annual Conference of the Association for Consumer Research, 382-93. Chicago: Association for Consumer Research. http://acrwebsite.org/volumes/12016/volumes/sv02/SV-02.

67- Roselius, Ted. 1970. "Consumer Rankings of Risk Reduction Methods." Journal of Marketing 35 (1): 56-61. doi: $10.2307 / 1250565$.

68- University of Texas. 2015. "Todd Humphrey's Research Team Demonstrates First Successful GPS Spoofing of UAV". University of Texas. http://www.ae.utexas.edu/news/504-toddhumphreys-research-team-demonstrates-first-successful-uavspoofing

69- Rao, Bharat, Ashwin Goutham Gopi, and Romana Maione 2016. "The societal impact of commercial drones". Technology in Society 45(1), 83-90.

70- Abbas, Hassan. 2013. "How Drones Create More Terrorists." The Atlantic. https://www.theatlantic.com/international/archive/2013/08/how -drones-create-more-terrorists/278743/.

71- Clarke, Roger. 2014. "The Regulation of Civilian Drones' Impacts on Behavioural Privacy." Computer Law and Security Review 30 (3). Elsevier Ltd: 286-305. doi:10.1016/j.clsr.2014.03.005.

72- European RPAS Steering Group. 2013. "Roadmap for the Integration of Civil Remotely - Piloted Aircraft Systems into the European Aviation System - Final Report from the European RPAS Steering Group - ANNEX 1," no. June: 1-54. 